Rudolf Richter, Frankfurt, wurde zum auswärtigen Mitglied der Geological Society of London gewählt.

G. Solle wurde im November 1948 zum apl. Professor an der Universität Frankfurt a. M. ernannt, nachdem er dort seit dem 1. Juli 1948 eine Diäten-Dozentur inne hatte.

Rudolph Staub, Zürich, wurde am 29. Januar 195060 Jahre alt.

CURT TeIChert in Melbourne erhielt für seine Arbeiten in Westaustralien den David-Serme-Preis, der als der am meisten angesehene wissenschaftliche Preis in Australien gilt.

E. Wegmann wurde zum Vizepräsidenten der Geologischen Gesellschaft von Frankreich ernannt.

\title{
GEOLOGISCHE VEREINIGUNG
}

\section{Jahresversammlung 1951}

Die Jahresversammlung der Geologischen Vereinigung 1951, die der Paläoklimatologie gewidmet sein soll (vgl. G. R. Bd. 37, S. 139-140), wird auf Beschluß der letzten Jahresversammlung vom 6.-7. Januar 1951 in Köln stattfinden. Um die Diskussion möglichst fruchtbar zu gestalten, sollen schon mit der Einladung kurze Inhaltsangaben der Vorträge übersandt werden. Würden Sie daher bitte Anmeldungen von Vorträgen mit entsprechender, möglichst kurz zusammengefaßter Inhaltsangabe (10-20 Zeilen werden meist genügen) bis spätestens 1. Nov. 1950 an Prof. Schwarzbach, Köln, Zülpicher Str. 47, richten.

Der Bericht über die J a hresvers a m m lung 1950 erscheint im 1. Heft des Bandes 39, 1951. Über die Verleihung der Gustav-Steinmann-Medaille und von Ehrenmitgliedschaften wird im nächsten Heft von Band 38 berichtet werden.

Eine neue Mitgliederlis te soll in einem der nächsten Hefte erscheinen. Deshalb werden vorher keine Ergänzungslisten mehr gedruckt. 